\title{
Reactualizando alianzas al pie de la Cordillera de los Andes: el parlamento de 1816 entre pehuenches y patriotas
}

( Martín R. Vilariño*

Fecha de recepción: 10 de marzo de 2020. Fecha de aceptación: 23 de abril de 2020

Palabras clave

parlamento pehuenches San Martín Mendoza

\section{Resumen}

El artículo analiza el parlamento que mantuvieron las parcialidades pehuenches y José de San Martín en 1816 en el fuerte de San Carlos (Mendoza). En nuestro análisis pretendemos apartarnos de las interpretaciones clásicas del evento que solo se han centrado en la perspectiva de los patriotas, buscando entender los alcances y las repercusiones que tuvo en las parcialidades indígenas. Para ello consideramos que es necesario encuadrar dicho parlamento en la dinámica fronteriza que se gestó en Cuyo durante los últimos años del período colonial y los primeros años del siglo XIX. En estos años se construyeron relaciones socio-políticas y tuvieron lugar hechos en la frontera cuyana que ayudan a entender los orígenes y las características del parlamento de 1816.

\section{Updating alliances at the feet of the Cordillera de los Andes: the 1816 parlamento of Pehuenches and patriots}

\section{Abstract}

Key words parliament Pehuenches San Martín Mendoza
The article analyzes the parlamento (diplomatic ritual) held by Pehuenche factions and José de San Martín in the fort of San Carlos -currently province of Mendozain 1816. Our analysis intends to move away from classic interpretations of the event that focused mainly on the patriots' perspective, and instead seeks to understand its scope and repercussions on indigenous groups. In order to do so, we consider it necessary to contextualize this parlamento within the frontier dynamics that took place in Cuyo during the late colonial period and the early 19th century. During this period, socio-political relationships were built and events occurred on the Cuyo border that help us understand the origins and characteristics of the 1816 parliament. 


\section{Introducción}

El siguiente trabajo pretende contribuir a comprender y complejizar las dinámicas fronterizas y los vínculos políticos entablados entre los distintos actores en Cuyo durante los primeros años del siglo XIX. Si bien el presente artículo busca describir y analizar el parlamento entre las parcialidades pehuenches y José de San Martín, éste se inscribe dentro de una problemática mayor, la cual consiste en identificar y problematizar la agencia indígena en el centro-sur de Mendoza y el norte neuquino durante la primera mitad del siglo XIX. ${ }^{1}$ El Parlamento se realizó en 1816, en el marco de las relaciones interétnicas desplegadas en la frontera de Cuyo. En nuestro análisis e interpretación del evento pondremos el foco en los vínculos diplomáticos que mantuvieron indígenas y patriotas durante la década de 1810. En otras palabras, pretendemos indagar cómo se configuraron las dinámicas fronterizas y las relaciones interétnicas entre criollos e indígenas a comienzos de la década de 1810, para posibilitar la concreción de un parlamento entre San Martín y los principales líderes pehuenches.

Este encuentro, en ocasiones es denominado "La Consulta" por habitantes de Mendoza a raíz de que en el ideario popular José de San Martín se reunió con los pehuenches para pedirles permiso para que lo dejasen pasar a él con su ejército por sus territorios. Según esta creencia este encuentro habría dado pie a que se fundase el pueblo de La Consulta, ubicado en el departamento mendocino de San Carlos (Morales Guiñazú, 1938; Chaca, 1964; Pérez, 1996; Piattelli, 2014). Aquí la idea central es que el parlamento de 1816 no se habría producido en el fuerte de San Carlos sino sobre estas tierras, las cuales están a una distancia de nueve kilómetros. Esto fue descartado por Dionisio Chaca al sostener que no solo hay suficiente documentación para aseverar que dicho encuentro se dio en el fuerte sino que además recuperó un archivo judicial de Mendoza de acuerdo al cual para 1705 Diego Moyano Cornejo reclamó una estancia en donde uno de sus límites al norte era un abra que los indígenas denominaban "la consulta"2 (Chaca, 1964; Gattas, 2018).

A su vez, este encuentro es ampliamente citado y analizado por la tradición historiográfica cuando se aborda la vida de San Martín y su actuación política en Cuyo. Esto implica que en muchas ocasiones las investigaciones se centraran en él, a partir de la óptica criolla, sin tener en cuenta la relevancia que tuvo para los indígenas; descontextualizándolo así de las lógicas diplomáticas establecidas entre ambos grupos. A su vez, a pesar de que son numerosos los autores que mencionan este parlamento la mayoría lo hace de forma superficial, y a partir de lo dicho por una serie de autores que podemos denominar como "clásicos" a la hora de estudiar la figura de San Martín y la independencia de Argentina y Chile, como John Miller ([1828] 1997), Bartolomé Mitre ([1875-1887] 1968), Gerónimo Espejo, (1882), Diego Barros Arana (1857 y 1889) y Ricardo Rojas ([1933] 1961). ${ }^{3}$ Estos cinco autores tienen en común varios aspectos: parten de la descripción del parlamento realizada por Miller al confeccionar las memorias de su hermano William; analizan el encuentro desde la óptica de las estrategias políticas y militares desplegadas por San Martín en el contexto de las guerras de independencia; utilizan un corpus de documentos escasos y similares -en algunos casos utilizan los mismos documentos-; ${ }^{4}$ en la mayor parte de los casos plantean al parlamento como una estrategia de San Martín dentro de la "guerra de zapa", destinada a engañar tanto a indígenas como a realistas; y destacan el carácter deshonesto de los indígenas hacia San Martín.
1. Dentro de esta problemática mayor tratamos de identificar, entre otros, las configuraciones territoriales de las distintas parcialidades y las redes de relaciones sociopolíticas que intervinieron en estos espacios; los intereses políticos indígenas y su incidencia en la diplomacia fronteriza; los orígenes y las características de los diferentes dispositivos fronterizos -como los parlamentos-; y las construcciones identitarias de los grupos indígenas.

2. Esto puede estar indicando que la región se conocía desde hacía mucho tiempo por este nombre y que seguramente era un lugar donde las distintas parcialidades indígenas se reunían para debatir sus propias problemáticas. A su vez, el hecho de que se cite la existencia de este punto geográfico no nos está indicando cuándo se fundó el pueblo que actualmente lleva por nombre La Consulta. En cuanto a la fecha de origen de La Consulta lamentablemente no hemos podido precisarla. En los mapas de Mendoza consultados no lo hemos encontrado mencionado antes de 1880. Por un lado, Chaca (1964) expone un croquis de la Villa de San Carlos para 188 o en donde se deja constancia de la existencia de este lugar. (Continúa en página 88).

3. Algunos autores además citan a Manuel de Olazábal ([1855] 1978), quien supuestamente habla de otro parlamento realizado a fines del mismo año. Nosotros, al realizar el relevamiento bibliográfico, no pudimos encontrar dicha mención por parte del autor a ese parlamento. También se puede agregar la obra de José Miguel Yrarrázaval Larraín (1949), autor que por lo que observamos, es escasamente citado.

4. Cartas en donde San Martín responde una serie de preguntas realizadas por William (Guillermo) Miller, sin fechas, AGN, Sala VII 7-36; Fondo Ángel Justiniano Carranza (utilizadas por John Miller y por Yrarrázaval Larraín); Carta de San Martín a Tomas Guido fechada el 24 de septiembre de 1816 , AGN, Sala VII 16-01-01. (Continúa en página 88). 
5. Sobre los parlamentos se ha escrito mucho hasta el momento, nuestra intención no es realizar un estado de la cuestión detallado sobre el tema sino retomar los estudios que han influenciado nuestra mirada sobre los eventos.

6. Esta es una nota enviada por $\mathrm{Pa}$ blo Millalican a Toribio Luzuriaga el 25 de septiembre de 1816 . AGN, Sala $X_{4-3-5, \text { F. } 427 .}$
7. Levaggi (2000) al recopilar y analizar los diversos parlamentos entre indígenas e hispano-criollos en la frontera pampeano-patagónica considera que fueron verdaderos tratados internacionales objeto del derecho internacional. Esto se debe a que en estos encuentros se reconocieron multiplicidades de naciones indígenas con las cuales los españoles establecieron distintos tipos de acuerdos (Nacuzzi, 2006).
Entonces, como propuesta alternativa a las interpretaciones de la historiografía clásica y para entender los alcances del parlamento de 1816 proponemos contextualizarlo y analizarlo dentro de la dinámica política y social de la frontera de la región de Cuyo a comienzos del siglo XIX. De esta forma, pretendemos tratar de rescatar los alcances y posibles significados que pudo tener para las parcialidades indígenas. Antes de adentrarnos en la descripción y el análisis del parlamento y del contexto fronterizo en el que se suscribió, creemos menester dar cuenta de algunos debates en torno a los parlamentos. Para esto retomaremos algunos autores que nos sirvieron para reflexionar sobre los encuentros diplomáticos interétnicos. ${ }^{5}$

Con respecto a las fuentes utilizadas para el presente artículo, recurrimos a documentación edita e inédita hallada en el Archivo General de la Provincia de Mendoza, Fondo Período Independiente (en adelante, AGPM, PI) y diversos fondos asociados a Cuyo y las fronteras de las salas X y VII del Archivo General de la Nación (en adelante, AGN). Hay que destacar que hasta el momento no hemos podido encontrar documentación producida por los propios indígenas para la época a trabajar, a excepción de una carta. ${ }^{6}$ Esto nos hace más difícil la tarea de recuperar las voces de los propios actores indígenas pues aun cuando no están totalmente invisibilizadas, están mediatizadas por los criollos que las transcribieron. Por tal motivo debemos ser cuidadosos al tomar posturas esquemáticas a la hora de interpretar la agencia indígena. Además, tampoco encontramos, si es que existió, el acta del parlamento realizado en 1816 entre los pehuenches y los patriotas, ni encontramos mención alguna que sugiriera la posible existencia de dicha acta. La única versión sobre el desarrollo del parlamento es la realizada por Miller ([1828] 1997).

\section{Parlamentos en el mundo fronterizo: algunos planteos teóricos}

El parlamento es un elemento de importancia a la hora de entender las relaciones intra e interétnicas, estando asociado directamente a la noción de frontera (Boccara, 2002) y de política fronteriza, al punto de que en ocasiones se considera al parlamento como la principal institución de negociación en esos espacios. Al sur del continente americano los parlamentos entre indígenas y europeos tuvieron origen a fines del S. XVI en la zona del Biobío; se consolidaron durante los S. XVII y XVIII para lograr su mayor impacto en la frontera a fines del S. XVIII (Zavala et al., 2015). A raíz de su importancia a la hora de entender las dinámicas fronterizas suscitó gran interés entre los investigadores. Según Carlos Lázaro (2002), los primeros abordajes al tema estuvieron dados por los historiadores del derecho, como Alamiro de Ávila Martel (1973) y Abelardo Levaggi ${ }^{7}$ (1992, 1993 y 1995), a los cuales se sumaron los trabajos del antropólogo José Miranda Borelli (1984) y de la historiadora Luz María Méndez (1982). Para Lázaro, aunque estos trabajos abrieron nuevos enfoques para el estudio del fenómeno diplomático fronterizo, ninguno tuvo interés en esclarecer cuál fue el origen de esta institución. Según dicho autor, las primeras referencias jurídicas sobre los parlamentos entre indígenas y europeos serán los encuentros entre Colón y los tainos y los que tuvieron lugar en las guerras chichimecas y tlaxcaltecas; y si bien serían efímeras a causa de la conquista, las experiencias de estos grupos indígenas sirvieron de antecedente y de base para la aplicación de los tratados en las fronteras del sur de América, tanto en la región de la Araucanía como en las Pampas (Lázaro, 2002). Ambos antecedentes se plasmaron tanto en la obra del jesuita Luis de Valdivia como en el origen de la guerra defensiva en la Araucanía. El accionar del religioso y el fomento de la guerra defensiva por sobre la guerra ofensiva consolidó al 
parlamento como medio preponderante para que se relacionen e interactúen dos mundos diferentes pasando a ser un ámbito de aparente consenso entre ambos grupos, o sea el hispano y el indígena

Otro aspecto para destacar del trabajo de Lázaro (2002) es que identifica similitudes y diferencias entre los parlamentos de la Araucanía y de las Pampas. La primera diferencia es el período en que se desarrollaron a ambos lados de la Cordillera. Cuando los jesuitas empezaron a actuar en las Pampas con el fin de evangelizar a los grupos indígenas, en Chile ya llevaban largo tiempo actuando y debatiendo sobre el tema. ${ }^{8}$ La segunda diferencia es que en las Pampas el peso diplomático recayó en los gobernadores y militares, mientras que en Chile lo hizo en los religiosos. La tercera diferencia reside en que mientras la línea de frontera en Chile, delimitada por el Biobío, era relativamente perdurable y estable, la frontera bonaerense cambió constantemente hasta el tratado de 1742, el cual fijó el límite en el Río Colorado. Una cuarta diferencia reside en que en el ámbito pampeano hubo una preponderancia mayor de las exhibiciones de caballería indígena durante los momentos previos al parlamento, y que en esta región el mismo era sellado con un mero estrechamiento de manos entre los participantes.

Además de referirse al origen de las formas parlamentarias y de las diferencias entre los parlamentos de la Pampa y la Araucanía, Lázaro (2002) analiza las características generales de los parlamentos. Algo a destacar es que el autor distingue las figuras de las parlas o juntas (coyang) del parlamento (chravun), siendo las primeras reuniones al interior de las parcialidades indígenas y previas a los parlamentos, convocadas para tratar las temáticas a desarrollarse en los parlamentos con los hispano-criollos. En cuanto a los chravun sería un término más generalizador y englobaría a las reuniones mantenidas entre indígenas y europeos, convocadas con el fin de tratar las paces entre ambos grupos. Según el autor, el parlamento tuvo un carácter dual, oral y escrito, siendo una conjunción de las prácticas de ambos grupos. La oralidad fue un aporte indígena, como un elemento clave en tanto alternativa al convencimiento por el uso de la fuerza. Lo escrito, en cambio, fue una imposición de los españoles que se manifestó en el valor que fueron adquiriendo las actas y otros documentos relacionados al parlamento -por ejemplo, los pasaportes. De hecho, para españoles y criollos la validación jurídica de los parlamentos siempre estaba dada, en última instancia, por lo escrito. ${ }^{9}$

Para finalizar, hay que rescatar dos aspectos más de los que habla Lázaro; por un lado, el parlamento como forma de instaurar, por parte de los españoles, nuevas figuras jurídicas en el mundo indígena -como el Capitán de Amigos o el Cacique Gobernador, entre otros- y; por el otro, el papel preponderante que los indígenas le darán a la relación y el vínculo personal por sobre los aspectos institucionales, en los parlamentos.

José Manuel Zavala Cepeda (2008) complementa algunos aspectos trabajados por Lázaro haciendo hincapié en el carácter híbrido de los parlamentos. El mencionado autor parte de una definición inicial de parlamento en tanto encuentro entre autoridades españolas y representantes indígenas, realizado con el fin de establecer o ratificar un tratado de paz y/o reafirmar la obediencia de los indígenas a la Corona. Sin embargo, considera que es una definición que destaca un aspecto formal de los tratados, en donde tiene mayor relevancia el carácter escrito manifestado en las "capitulaciones" o "artículos", algo ya planteado por Lázaro. Siguiendo el argumento de Zavala Cepeda, este aspecto formal será tal vez el menos importante en los parlamentos, ya que
8. En Chile se comienza a parlamentar con los indígenas antes de que ocurra en el Río de la Plata, registrándose los primeros tratados en la región bonaerense a partir de 1716.

9. A estas características se sumó la utilización, en la región de Chile, de elementos rituales como el árbol del canelo, el Toqui y Chillihueque. La aceptación de estos elementos por parte de los españoles, en especial por los jesuitas, en la ritualidad llevada adelante en los parlamentos se debió principalmente a que fue una estrategia para atraerlos a parlamentar y, a la vez, para lograr un adoctrinamiento, ya que esto sirvió para equiparar símbolos mapuches con símbolos católicos. La paulatina asimilación de los símbolos hispanos en detrimento de los símbolos mapuches se verá en la equiparación del canelo con la cruz y el toqui con el bastón de mando. 
10. Aunque esta división es oportuna, entendemos que la realización de los parlamentos en ciudades españolas implicó una demostración de fuerza por parte de los españoles; la realización en fuertes fronterizos demostró un cierto grado de neutralidad en el encuentro y los parlamentos en espacios abiertos implicó un mayor peso de la política y de las fuerzas indígenas. Esto último se debe a que estos espacios abiertos, por lo general, estaban en lo que se denominó generalmente "tierra adentro"; o sea territorios indígenas. en la frontera chilena sobrepasó los límites de una mera reunión diplomática puntual. Esto hizo que el parlamento adquiera carácter de institución, convirtiéndose así en un acontecimiento social, económico y político en el cual no solo un grupo se mostraba ante un "otro", sino que también se transformaba en un espacio de contacto y comunicación transcultural. Según este autor, además, hay tres aspectos que hacen pensar al parlamento como más próximo al mundo mapuche que al mundo español: 1) el aspecto ritual; 2) que el medio de comunicación privilegiado fue el mapuzungun y el estilo discursivo el indígena -el valor de la oratoria y los ritmos de esta dentro del parlamento y 3) que el mecanismo político subyacente fuera la lógica de la "donación".

En línea similar a la anterior, Zavala Cepeda et al. (2015) analizaron los parlamentos entre mapuches y españoles entre 1593 y 1771 y los caracterizaron cómo momentos en donde no se plasmó el poderío español sobre los mapuches de una forma hegemónica. Al contrario, estaban tensionados por las imposiciones de las distintas parcialidades mapuches sobre los españoles. Esto se observa en algunas expresiones escritas en los documentos y en los lugares en que se llevaron adelante los encuentros. Con respecto a esto último los autores plantean que la realización de los parlamentos se puede clasificar en tres categorías, según el lugar en donde se realizaron: 1) en los fuertes españoles; 2) en las ciudades españoles y 3 ) en campos abiertos, lo que implicaba una cierta neutralidad en el encuentro (Zavala Cepeda et al., 2015). ${ }^{10}$

Por otro lado, Ingrid de Jong (2016) realiza un análisis comparativo de los tratados de paz en la Araucanía y las Pampas desde el periodo colonial hasta las últimas décadas del siglo XIX, cuando se llevan a cabo los últimos parlamentos entre los estados nacionales independientes y los grupos indígenas. De este trabajo hay varios aspectos a destacar. Por empezar la autora alude a la lógica del tratado de paz como un "hibrido social", al parlamentarismo como una institución sui generis, el cual fue un fenómeno a largo plazo vinculado estrechamente a los aspectos económicos-comerciales y a los conflictos territoriales inter e intraétnicos. Además rescata, siguiendo lo propuesto por Guillaume Boccara, el carácter disciplinador y de dominación de los parlamentos, siendo un elemento clave a largo plazo -junto a las prácticas militares con las cuales se fueron alternando- a la hora de concretar la dominación hispano-criolla sobre los grupos indígenas. Con respecto a este punto la mencionada autora muestra cómo en los parlamentos, en especial en aquellos celebrados en la Araucanía, la dominación española y criolla se fue manifestando en las condiciones de los tratados. Un tercer aspecto a destacar es el impacto diferencial que generaron los parlamentos en los grupos indígenas en ambos lados de los Andes. Al oeste encuentra una forma de parlamentar más estructurada y ritualizada y el impacto sobre los pueblos indígenas fue el de generar identidades englobantes. Al este, en cambio, se dio una forma muy distinta, generando en los indígenas una fragmentación identitaria y de las alianzas políticas.

Por su parte, Florencia Roulet (2016) retoma los aportes de Levaggi, Boccara, Claudia Briones, Morita Carrasco, Jorge Pinto Rodríguez y Zavala Cepeda, y plantea que los parlamentos y acuerdos escritos se inscribieron en lo que denomina "protocolos de tierra adentro", "una serie de reglas de etiqueta desglosadas en un continuum de instancias sucesivas, que a menudo resultan soslayadas en nuestros documentos y que a veces fueron parcialmente omitidas en la práctica" (Roulet, 2016: 193). Éstos, además, no solo regularon los comportamientos esperados para el ingreso con fines pacíficos a los territorios indígenas sino que estuvieron compuestos por una serie de momentos específicos claros y pautados, a los cuales la autora divide en: la presentación; la escolta 
familiar; el anuncio de llegada; las ceremonias de recibimiento; las parlas, la distribución de regalos; la incorporación del otro mediante el parentesco real o simbólico y, por último, el cumplimiento de las promesas. Cómo se verá más adelante, el parlamento entre los pehuenches y los patriotas comandados por San Martín se insertó en esta lógica.

A raíz de estos antecedentes, el siguiente trabajo parte de entender a los parlamentos como una institución netamente fronteriza, de carácter híbrido e interétnico y con una ritualidad y tiempos específicos, utilizada por los distintos actores como una herramienta política para alcanzar sus propios intereses políticos-económicos y no solo con fines de establecer las paces. A su vez, los parlamentos contaron con ciertas ritualidades, que se insertaron en un sistema fronterizo mayor en donde hallamos una multiplicidad de instituciones en relación.

\section{Diplomacia entre indígenas y patriotas en la región de Cuyo (1810-1816)}

Hacia fines del período colonial, luego de una serie de conflictos prolongados y costosos en hombres y recursos, los funcionarios coloniales lograron establecer una alianza y una paz relativamente estables con las distintas parcialidades pehuenches (Roulet, 2002, 2004 y 2016). Para lograr este clima político fue fundamental la participación de una serie de funcionarios que actuaron como "mediadores diplomáticos" (Barbuto, 2016), por ejemplo: los Comandantes de Frontera, los Comandantes del fuerte de San Carlos y San Rafael y el Cura conversor. Estos actores entablaron lazos de familiaridad con los distintos agentes indígenas, algo que era de utilidad a la hora de establecer los diálogos diplomáticos. Un ejemplo de esto fue lo ocurrido con José Francisco de Amigorena (Roulet, 2002, 2014 y 2016).

Luego del estallido revolucionario criollo en Buenos Aires en mayo de 1810, y del establecimiento de la Junta Grande, éste se extendió rápidamente al resto del antiguo territorio del Virreinato del Río de la Plata; entre ellos, a la Gobernación de Cuyo -compuesta por Mendoza, San Luis y San Juan. Dicho movimiento revolucionario repercutió a nivel político tanto al interior de los hispano-criollos como en el mundo fronterizo de esta región. En el plano político, se sucedieron diversos conflictos políticos-miliares al interior de los patriotas para dirimir no solo quien gobernaría la región, sino también los alcances de su jurisdicción (Zinny, 1987). ${ }^{11}$ Esto, a su vez, generó cambios en los funcionarios estatales vinculados a la frontera, con implicancias en las relaciones fronterizas.

Desde un comienzo, al instalarse en el Gobierno de Cuyo las autoridades patriotas buscaron mantener y fomentar los buenos tratos que se habían logrado con los indígenas durante el periodo colonial; y con ello la relativa paz en la frontera. Para esto no solo hicieron cambios en los puestos clave de gobierno clave en los vínculos fronterizos ${ }^{12}$ sino que además fomentaron el intercambio comercial y los encuentros diplomáticos. Ejemplo de esto son los informes presentados por Juan Nicolás Godoy ${ }^{13}$ y José Ferrari ${ }^{14}$ a la Real Hacienda a comienzos de 1811, o el parlamento que mantuvo Alejo Nazarre con distintos Caciques y Capitanejos en $1812 .{ }^{15}$ Estos intentos de los patriotas por mantener la estabilidad en las alianzas con las distintas parcialidades indígenas fueron reforzados por el ingreso de San Martín a la escena política de Cuyo, en 1814.
11. Para 1813 el Triunvirato de Buenos Aires decretó la creación de la Provincia de Cuyo, logrando así la independencia de Córdoba (Zinny, 1987; Molina, 2014).

12. Designando, o dejando bajo su cargo, a personas que adhirieran a la causa revolucionaria siempre que tuvieran algún conocimiento del mundo fronterizo, como fueron los casos de José de Susso, José León Lemos e Inalican. Durante este período ocuparán los cargos de Comandante de Frontera; Comandante del fuerte de San Carlos; y Cura conversor respectivamente.

13. AGN, Sala X, 41-1-2; Doc. 31,1 de abril de 1811.

14. AGN, Sala X, 41-1-2; Doc. 61, 8 de mayo de 1811 .

15. La Gaceta de Buenos Aires, junio de 1812 (Junta de Historia y Numismática Americana, 1911; Musicó, 1973; Bechis, 2001). 
16. Pichicolemilla fue el Cacique Gobernador de las parcialidades pehuenches de la zona de Malalhue, elegido en 1798 por acuerdo entre las autoridades coloniales y los principales caciques para suplantar a Millaguin luego del conflicto entre las parcialidades de Malalhue y las de Barbarco (Roulet, 1999-2001, 2002, 2016; León, 2001).

17. Millaguin fue hijo de Ancanamún y sobrino de Pichintur, ambos Caciques Gobernadores de Malalhue. A la muerte de su tío lo sucedió en el cargo de Cacique Gobernador de los pehuenches de las parcialidades de Malalhue hasta que fue suplantado por Pichicolemilla. Mientras Pañichiñe, fue un importante Cacique pehuenche hijo del Cacique Roco y hermano de la Cacica María Josefa Roco; cuando Pichicolemilla fue designado como Cacique Gobernador fue su segundo al mando (Roulet, 19992001, 2002, 2016; León, 2001).

18. Aunque Posadas, en calidad de Director Supremo, lo designa el 10 de agosto de 1814, San Martín asume efectivamente el cargo de Gobernador Intendente de Cuyo recién el 6 de septiembre de ese año (Galasso, 2007; Bragoni, 2010).

19. AGPM, PI, Capeta 123, Doc. 1. Folios1 y 2, S/F. AGPM, PI, Carpeta 234, Doc. 8o, Folio 25, 29 de octubre de 1814. AGN, Sala X, Carpeta 5-5-4, Folio 258, 11 de noviembre de 1814 . AGN, Sala X, Carpeta 5-5-4, Folio 258,11 de noviembre de 1814 .

20. AGPM, PI, Carpeta 23, $\mathrm{N}^{\circ} 655,11$ de octubre de 1814 . La respuesta a esta carta la podemos encontrar en Pavez Ojeda (2008)

21. El acta del parlamento en donde se destacan los detalles acordados del evento la podemos encontrar en AGPM, PI, Carpeta 234, Doc.8o. En cuanto al río San Pedro, Roulet (1999-2001) lo identifica como el río Malalhue.

22. Encontramos en la nómina de participantes un total de catorce Caciques y siete Capitanejos. Caciques: Neycuñam, Millatrin, Carripil, Lignancu, Paillayan, Calbical, Cathituen, Mañqueliu, Huirriñancu, Neyulem, Antiñan, Lincoñam, Caniuman, Llamiñamcu. Capitanejos: Lemunila, Antical, Lebianty, Reyñamcu, Huemical, Llamcan y Millatur. También figura Inalican en la nómina de Capitanejos. Como se puede apreciar, aquí están ausentes Caciques de relevancia política para la época como Millaguin, Pañichiñe, Pichicolemilla o la familia Goyco. Su ausencia nos estaría sugiriendo que en este parlamento con los patriotas solamente participaron los Caciques y Capitanejos de la parcialidad que respondía directamente a Neycuñan.
En paralelo a los intentos de los criollos por acercarse políticamente a los indígenas se dieron dos procesos de importancia que impactaron en las dinámicas fronterizas: el avance realista sobre los criollos patriotas en Chile y cambios en los liderazgos al interior de las parcialidades pehuenches. El fortalecimiento del poderío realista y la recuperación por parte de éstos del territorio chileno supuso un peligro, tanto para los patriotas rioplatenses como para los de Cuyo, pero también implicó un peligro directo para la estabilidad política que se trataba de mantener en la frontera; esto último a raíz de que los realistas hacían intentos por captar la ayuda militar de los pehuenches. Por su parte, los liderazgos indígenas sufrieron cambios para esta época. $\mathrm{Al}$ respecto, Pichicolemilla ${ }^{16}$ ya no era el Cacique Gobernador de las parcialidades pehuenches de Malalhué sino que ahora el cargo residía en manos de Neycuñan, quien lo sucedió entre 1812 y 1813. Además, para esta época los Caciques Millaguin y Pañichiñe ${ }^{17}$ comenzaron a tener más relevancia política en el mundo fronterizo. Es en estos momentos que la figura del Cacique Gobernador dejó de tener el trato preferencial en los vínculos diplomáticos, propio de la época colonial. En otras palabras, para los patriotas el Cacique Gobernador pasó a ser uno más de los tantos intermediarios fronterizos indígenas con los cuales entablar diálogo y alianzas, teniendo la misma importancia que otros líderes indígenas. Esto posibilitó que figuras que por uno u otro motivo estaban en un segundo plano en la esfera de la política fronteriza adquirieran mayor relevancia y visibilidad, como pueden ser los casos de Millaguin y Pañichiñe. Este fue, sucintamente, el panorama fronterizo y político con el cual se encontró San Martín al asumir como Gobernador Intendente de Cuyo a mediados de $1814 .^{18}$

Al momento de hacerse cargo del gobierno de Cuyo, San Martín era un completo desconocedor de lo que Roulet (2016) denomina "protocolos de tierra adentro"; o sea, de las reglas, "etiquetas" y formas de actuar y decir, sustentadas por vínculos entre los distintos actores y reciprocidades que las vehiculizaban y que permitían moverse en el mundo fronterizo y entablar acuerdos diplomáticos con las distintas parcialidades indígenas. En tal sentido, aceptó y siguió las distintas recomendaciones que le hicieron los "mediadores diplomáticos" como pudieron ser Susso, Lemos o Inalican. A pesar de ello, la presencia del Ejército realista en Chile hizo que comenzaran a crecer las tensiones y desconfianzas entre patriotas e indígenas, especialmente por las incursiones que los últimos hacían a Chile para comerciar. Con el fin de saldar estas rispideces y fortalecer los lazos de alianzas con los pehuenches, San Martín ordenó a Susso e Inalican realizar un parlamento con los principales Caciques y Capitanejos, el cual se concretó a finales de octubre de 1814 "tierra adentro" 19 (Pavez Ojeda, 2008). A comienzos del mes envió una serie de misivas dando directivas para el parlamento, entre ellas una a Inalican donde le indicaba que:

Los desgraciados suceso de Santiago de Chile, ponen a este Gov ${ }^{\text {no }}$. en la precisa obligación de buscar todos los medios a la seguridad de esta Prova. para este efecto ha dispuesto Parlamentar por medio del Comand ${ }^{\text {te }}$. Gral. de esa Frontera, V. P. al Gov ${ }^{\text {or }}$ y Casiques de la nación Pehuenche, con el objeto de $\mathrm{q}^{\mathrm{e}}$. asegurandoles nuestra amistad, den las noticias de los movimientos $\mathrm{q}^{\mathrm{e}}$. puedan hacer $\mathrm{p}^{\mathrm{r}}$. esa parte los enemigos de nuestra Sagrada Causa. ${ }^{20}$

Según la documentación analizada, éste se realizó el 23 de octubre de 1814 sobre el río San Pedro, ${ }^{21}$ cercano de las tolderías de Malalhue, y los asistentes fueron seguramente los Caciques y Capitanejos que respondían directamente a Neycuñan. ${ }^{22}$ En el mismo parlamento el Comandante de Frontera, José de Susso, no solo acordó nuevamente las paces con los pehuenches y les solicitó ayuda para combatir a los realistas que amenazaban la estabilidad 
revolucionaria desde Chile sino que leyó, mediante la asistencia de Inalican como traductor, el pliego que San Martín le había enviado para la ocasión. En él se expresan las intenciones del Gobernador de Cuyo de buscar la colaboración de los pehuenches para la seguridad de la frontera e integrarlos a su sistema de aliados para enfrentar a los realistas.

Desde mi ingreso a este Gov ${ }^{\text {no }}$. ha sido uno de mis primeros cuidados saber de todos vosotros y cuidar de Vuestra seguridad, y al efecto me he informado del Comand ${ }^{\text {te }}$. Gral. de esa Frontera, quien me ha hecho los mas expresibos elogios asi de la amistad q $\mathrm{q}^{\mathrm{e}}$. nos profesais como del interés $\mathrm{q}^{\mathrm{e}}$. tomais en la causa de nuestra libertad que es igualm ${ }^{\text {te }}$. vuestra: estos motivos os han colocado en el mas alto grado de mi aprecio $q^{e}$. quiero demostraros comisionando ante vosotros al mismo Comand ${ }^{\text {te }}$. Gral. En consorsio del Padre Capellan y Cura Conbersor Fry. Francisco Ynalican por cuyo medio os manifestará el comisionado mis sentimientos hacia vosotros [...] Descansad en la proteccion de este $\mathrm{Gov}^{\text {no }}$. y recibid los brazos q $\mathrm{q}^{\mathrm{e}}$. os embio como el mejor de vuestros hermanos. $^{23}$

El resultado fue positivo ya que ambos grupos acordaron mantener la paz y las relaciones diplomáticas. Esto se cumplió a lo largo de 1815 y 1816 no sin tensiones y rispideces, en especial entre los pehuenches y los comerciantes y hacendados criollos. Ante esta situación intervinieron los funcionarios estatales, entre ellos el propio San Martín, para apaciguar los ánimos. Por lo general, estos conflictos fueron resueltos en favor de los primeros. ${ }^{24}$ Además, en estos años se registraron varias visitas de los indígenas a los puestos fronterizos y a la ciudad de Mendoza para comerciar y recibir raciones por parte del gobierno patriota.

En 1816 se produjo un hecho que tensionó el clima existente en la frontera, y dio pie tanto a que las distintas parcialidades pehuenches confirmaran nuevamente su apoyo a los patriotas de Cuyo como al parlamento con San Martín. El hecho en cuestión fue la fuga del Coronel realista Agustín Huici, ${ }^{25}$ la cual puso en alerta a los cuyanos ya que pretendía dirigirse desde Córdoba -lugar donde se había fugado- hasta Chile para unirse a las fuerzas españolas. Para lograr su objetivo tenía que atravesar Cuyo o hacerlo a través de "tierra adentro". Ante tal situación, San Martín ordenó al Comandante de Frontera que hablara con los caciques, para la captura del jefe realista, y les ofreciese "quantos premios y gratificaciones le dicte su prudencia para $\mathrm{q}^{\mathrm{e}}$. activam ${ }^{\text {te }}$. cooperen a esta captura interesante" ${ }^{26}$ Ante esto, Susso envió al fray Inalican para que hablara con los principales caciques -como Millaguin, Neycuñan y Pañichiñe- y les ofreciera trecientas yeguas, tres arrobas de tabaco, papel, diez frenos -seis con copa y cuatro sin ella-, ${ }^{27}$ a lo que estos accedieron. El Coronel fue capturado por los pehuenches y entregado por el Cacique Gobernador a las autoridades patriotas. ${ }^{28}$ La recompensa, no obstante, se pospuso y las partes acordaron que se hiciera efectiva en el parlamento pensado para septiembre de ese año.

\section{Parlamento de 1816: el encuentro entre los pehuenches y San Martín}

A nuestro entender el parlamento entre distintas parcialidades pehuenches y el Gobernador de Cuyo respondió a la necesidad de este último de corresponder la actitud de los principales Caciques al capturar al militar realista y, de esta forma, reactualizar las alianzas con los indígenas. Mientras Huici era capturado San Martín decidió organizar un parlamento con los pehuenches,
23. AGPM, PI, Carpeta 23, N648, 11 de octubre de 1814 .

24. Esto se puede ver en los reclamos en torno a varios conflictos, por ejemplo cuando el Cacique Pitoñan acusó ante el gobierno de Mendoza al hacendado Antonio Hermida de querer sacarles sus tierras, ante lo cual San Martín ordenó que se detenga el desalojo hasta que Hermida pueda dar cuenta de que esas tierras eran de su propiedad (A GPM, PI, Carpeta 23, Doc. 3, $\mathrm{N}^{\circ} 270,26$ de febrero de 1816). Otra ocasión fue cuando los patriotas decidieron cerrar los distintos pasos que atravesaban el río Diamante, algo que afectó a varias parcialidades y luego de varias quejas por parte de los indígenas se decidió abrirlos nuevamente (AGPM, PI, Carpeta 237, Doc. 76, Folio 71, 6 de octubre de 1815; Carpeta 23, Doc. 2, $\mathrm{N}^{\circ} 1717,6$ de octubre de 1815; Carpeta 237, Doc. 94, 1 de diciembre de 1815; Carpeta 23, Doc. 2, N²357, 29 de noviembre de 1815; Carpeta 23, Doc. 2, $\mathrm{N}^{\circ} 2450,6$ de diciembre de 1815; Carpeta 237, Doc. 94, Folio 90, 7 de diciembre de 1815).

25. Huici fue un Coronel español, bajo las órdenes de Pio Tristan, derrotado por Díaz Vélez en el Combate de las Piedras, en Septiembre de 1812. De ahí fue trasladado como prisionero de guerra al fuerte de Santa Catalina en Río Cuarto desde donde se fugó.

26. AGPM, PI, Carpeta 23, Doc. 3, $\mathrm{N}^{\circ}$ 475, 14 de abril de 1816.

27. AGPM, PI, Carpeta 234, Doc.1, 30 de abril de 1816 (Pavez Ojeda, 2008: 143).

28. AGPM, PI, Carpeta 239, Doc. 36,16 de mayo de 1816 , Carpeta 23 . Doc. 3, N 616, 16 de mayo de 1816; Carpeta 240, Doc. 17, Folios 12-14, 20 de mayo de 1816 . 
29. AGPM, Pl, Carpeta 239, Doc. 45, F. 15, 15 de agosto de 1816. José León Lemos a José de San Martín, San Carlos.
30. AGPM, PI, Carpeta 23, Doc. 3, $\mathrm{N}^{\circ}$ 880,9 de septiembre de 1816 .

31. No tuvimos oportunidad de encontrar este documento en ninguno de los archivos consultados. Accedimos a él pues el autor mencionado lo reproduce en su totalidad y, a continuación del mensaje de San Martín, reproduce la respuesta que le envía Pueyrredón el 1 de octubre: "Espero el resultado de la entrevista a que usted se dirigía con los indios; si usted les ha llevado buenos regalos habrá sido todo consiguiente, porque tal es el mejor agente de sus afectos humildes" (Yrarrázaval Larraín, 1949: 96. Aparece una copia de dicha carta en: Documentos para la historia del libertador General San Martín 1954, T. IV; 225). Mientras tanto en una carta enviada el mismo 1 de octubre a San Martín por Florencio Terrada dice: "Se ha recibido el oficio de vuestra señoría de 10 del próximo anterior en que participa su salida para el Fuerte de San Carlos a tratar con los indios pehuenches sobre los puntos que detalla, dejando entretanto el mando del ejército en el Brigadier Don Bernardo O'Higgins. Lo aviso a nuestra señoría de orden suprema en contestación" (Documentos para la historia del libertador General San Martín, 1954, T. IV: 230). comenzando los preparativos a mediados de agosto de 1816. Para esta época, el Gobernador de Cuyo dio directivas al Comandante del fuerte de San Carlos para que les avisase a los caciques que se aprestaran para el encuentro. Ante esto, Lemos les informó que ahí se les darían las yeguas prometidas por la captura del jefe realista:

Cumplíendose con la orden de VS. mande el dose del presente á Anunciar a los Casiques de la Nacíon Peguenche que $\mathrm{p}^{\mathrm{a}}$. el primero del dentrante mes los esperaba VS. en esta fortalesa para selevrar el Parlamento y qe. Resíviesen las Yeguas que se les avian prometido. ${ }^{29}$

Esto nos hace pensar que el verdadero motivo que tuvo San Martín para impulsar el parlamento no solo fue agradecer la captura de Huici sino también como una forma ritual de actualizar y reafirmar la amistad entre patriotas e indígenas en un contexto político y social tenso y conflictivo marcado por los enfrentamientos entre sectores patriotas y realistas. Aunque la lógica e intención militar estuvo presente en este parlamento, en ningún momento la documentación analizada nos da a entender que el encuentro de 1816 fue pensado para engañar a indígenas ni a realistas. Es por estos motivos que hacemos hincapié en la idea de que a este parlamento hay que entenderlo dentro de la lógica diplomática que tanto criollos como indígenas mantenían desde 1810 pero con mayor intensidad desde 1814 . Consideramos al parlamento de 1816 como un evento de importancia, tanto para los indígenas como para los patriotas, a raíz de la relevancia simbólica y política que revestía este encuentro pero que, a su vez, estaba inserto dentro de una dinámica y lógica fronteriza preexistente y de larga data. A partir de 1814 San Martín ingresó a la vida política de Cuyo lo que implicaba interiorizarse de las dinámicas propias de la frontera, ya que para aquel momento los indígenas eran actores políticos fundamentales. Luego de este año, los principales Caciques y Capitanejos siguieron entablando vínculos cotidianos con el gobierno de Mendoza, lo que implicó que el nuevo Gobernador de Cuyo conociera muy bien quiénes eran estos actores para 1816.

Durante los primeros días de septiembre, San Martín se comunicó con una serie de colaboradores y aliados -entre otros, Susso, Juan Martín de Pueyrredón y Tomas Godoy Cruz- y les transmitió sus intenciones de reunirse con las parcialidades indígenas y sus directivas vinculadas a dicho encuentro. Al Comandante de Frontera le avisó que el fray Inalican partía hacia San Carlos y que él mismo lo haría al día siguiente pasando la noche en El Lujan para estar el día 11 en el Totoral y esperar con la escolta de granaderos a los Caciques. ${ }^{30}$ A Pueyrredón, Director Supremo de Buenos Aires, le escribió:

Reservado. Exemo. Señor. He creido del mayor interés tener un parlamento general con los indios pehuenches con el doble objeto, primero, el que si se verifica la expedición a Chile me permitan el paso por sus tierras; $\mathrm{y}$, segundo, el que auxilien al ejercito con ganado, caballadas, y demás que esté a sus alcances a los precios o cambios que se estipularan. Al efecto se hallan reunidos en el "Fuerte de San Carlos" el Gobernador Necuñán y demás caciques por lo que me veo en la necesidad de ponerme hoy en marcha para aquel destino, quedando en el entretanto mandando el ejército el señor Brigadier don Bernardo O’Higgins (en Yrarrázaval Larraín, 1949: 96). ${ }^{31}$

Como en otros parlamentos, este encuentro requería cumplir los "protocolos de tierra adentro" (Roulet, 2016), lo que implicaba seguir y respetar una serie de pasos previos al parlamento, durante y después del mismo. Un paso previo 
era el aviso anticipado del ingreso a los territorios indígenas, el cual San Martín ya había cumplido mediante los intermediarios fronterizos. Otro requisito era la entrega de regalos como una forma de demostrar el respeto y la amistad entre los participantes. En paralelo al aviso del encuentro a los caciques, San Martín organizó el viaje y se encargó de los regalos que llevaría al encuentro para obsequiárselos a los líderes pehuenches:

Para obsequiar al Govºr. y demás Casiques de los Peguhenches $\mathrm{q}^{\mathrm{e}}$. deben concurrir a un Parlamento a que los ha combocado este $\mathrm{Gov}^{\text {no }}$. El $1^{\circ}$ del próximo Sept ${ }^{\mathrm{e}}$. es de necesidad apronte V. los artículos siguientes $=\left(\mathrm{Vta}\right.$.) $2 \mathrm{lb}^{\mathrm{s}}$. de añil $=12$ frenos con copas $=12 \mathrm{id}$. Sin ellas $=3$. doz . estribos amarillos $=$ 3 id. De espuelas id. $=3$ pares id. de plata $=3$ sombreros con galon ord ${ }^{\circ} .=3$. Doz . de id. con cinta $=10$ mazos de chaquiras $=218$ pañuelos de Muselina = Cuyo importe lo cargará V. a los fondos públicos de su manejo, debiendo estar pronto a primer aviso de este $\mathrm{Gov}^{\text {no }} .=$ Dios $\mathrm{G}^{\mathrm{a}} .^{32}$

A pesar de los intentos patriotas de realizar el encuentro el 1 de septiembre éste se pospuso ya que los indígenas enviaron chasques informando que no podrían asistir por las intensas nevadas en sus potreros en la cordillera, donde se hallaban buscando su ganado caballar. ${ }^{33}$ Finalmente el encuentro se realizó el 18 de ese mes $^{34}$ en el fuerte de San Carlos. Del desarrollo del parlamento no hemos encontrado más registro que el de Miller, al confeccionar la biografía de su hermano William, quien a su vez reconstruyó el hecho a partir de lo narrado por el propio San Martín ${ }^{35}$ (Villegas, 1947; Vignati, 1953). A pesar de considerar que el relato de Miller es poco confiable, no solo porque no estuvo presente en el parlamento y sino también porque el testimonio que recogió del propio San Martín fue mucho tiempo después de ocurrido el mismo, es el único registro que hasta el momento existe al respecto. Conscientes de ello, no obstante, su relato ofrece alguna información valiosa. En él se puede apreciar cómo estuvo estructurado el parlamento y las ritualidades protocolares que se desplegaron; observándose elementos propios de las formas de hacer los parlamentos en Pampa-Patagonia -cómo la importancia de la ritualización del encuentro manifestada en la recreación de un acto de guerra, el desfile militar previo a parlamentar y el carácter personalista del parlamento expresado en la participación del propio San Martín, máxima figura política y militar de Cuyo en aquel entonces. En lo dicho por Miller se lee lo siguiente:

A las ocho de la mañana del -de Septiembre de 1816, los casiques se aproxîmáron á la esplanada del fuerte con el todo de la pompa de la vida salvage, á la cabeza de su gente de guerra, trayendo á retaguardia á sus mujeres y sus hijos [...] hombres y caballos tambien iban aderezados en la misma forma que cuando van á la guerra; en fin, hombres y caballos estaban como para el acto del combate. A cada casique le precedia una pequeña partida de caballería del ejército patriota, enviada por el general para en proporción de que la tribu avanzára hacer fuego sin balas con sus pistolas en forma de salva ó celebridad, pues este modo de introducir á los Indios á la presencia de los Cristianos es un cumplido ó etiqueta que jamás dispensan [...] Cuando todas las tribus llegarón, los guerreros de una de ellas principiáron un simulacro de un combate durante el qual mantuviéron sus caballos al escape, ó los hacían volver repentinamente sobre las piernas, dar corvetas y saltar y hacer cabriolas alrededor en la manera mas extraordinaria. Durante estos egercicios, un cañon del fuerte disparaba cada cinco minutos, á cuyo saludo constestaban los Indios dándose palmadas en la boca, y dando los mas horrorosos aullidos en señal de contento [...] Estos marciales ejercicios duráron hasta la tarde, y la escolta del
32. AGPM, PI, Carpeta 23, Doc. 3, N 819,19 de agosto de 1816 .

33. AGPM, PI, Carpeta 239, Doc. 45, Folio 16, 23 de agosto de 1816.

34. AGPM, PI, Carpeta 485, Doc. 38, Folio 277,25 de septiembre de1816.

35. Estas memorias fueron publicadas en 1828 , casi doce años después del hecho, mediante la recopilación de varios fragmentos de diarios personales, cartas y entrevistas que su hermano William sostuvo con distintos actores que habían participado en las guerras de independencia; siendo una de estas personas San Martín. A lo largo de varios años William Miller se escribió con él sobre diversas temáticas, entre ellas el parlamento con los pehuenches. En tres de estas cartas San Martín respondió sobre el parlamento y describió el evento y al pueblo pehuenche, información que Miller transcribió en las memorias de su hermano (AGN, Sala VII 7-3-6; Fondo Ángel Justiniano Carranza, Páginas 46 [respuesta $\mathrm{N}^{\circ}$ 3], 61 [respuesta $\mathrm{N}^{\circ} 8$ y 9] y 64 [respuesta 4]. Cabe aclarar que las cartas carecen de fecha o alguna referencia que pueda indicar su datación. No cabe reproducir estas respuestas ya que fueron publicadas en parte por Alfredo Villegas (1947). Siguiendo a Villegas, también es necesario aclarar que San Martín da una serie de datos que Miller omite o reformula a la hora de realizar la reconstrucción del parlamento. 
general San Martin, compuesta de una compañía de caballería y doscientos milicianos, permanecieron formados en orden de parada.

Publicado el momento de entrar á conferenciar, estas se principiáron en la plaza de armas, donde el gobernador del castillo habia preparado una mesa cubierta con el paño de un púlpito y bancos para los casiques y capitanes á guerra, que fueron las únicas personas asmitidas á conferenciar con el general. Los Indios, en la parte exterior, permanecieron formados y montados, manteniéndose alerta hasta saber el resultado.

Al llegar á la plaza de armas fuéron sentándose con arreglo á su dignidad, primero los caciques y luego los capitanes de guerra. El general San Martin, el gobernador del fuerte, y el intérprete se colocaron en un banco á la cabecera de la mesa. Como un acto de cortesía, el general les ofreció amigablemente una copa de vino, ántes de entrar en negocios [...] Entonces el intérprete, que lo era el padre Julian del orden de San Francisco, Araucano de nacimiento y criado por una familia criolla desde la edad de diez años, les hizo una arenga, en la cual les recordó la buena intenligencia y amistad que habia existido entre los Indios Pehuenches y el general en jefe; que confiaba en la continuación de la armonía felizmente establecida entre llos; y que los convocaba á una solemne conferencia para cumplimentarles ofreciéndoles algunas bebidas y regalos, y pedir permitieran pasar al egército patriota por el territorio de Pehuenche para atacar á los Españoles [...] Un Profundo silencio siguió á esta arenga [...] Al fin el casiquec mas antiguo, llamado Ninconyancu, rompió el silencio: esta era un anciano de cerca ochenta años [...] al dirigir su discurso á sus hermanos, los otros gefes de las tribus, les pregunto con tranquila circunscripción, si eran de opinión que las propuestas que acababan de hacer los Cristianos debían ó no aceptarse [...] Cada gefe a su turno manifestó su opinión con la mayor tranquilidad [...] Convencidos en la contestación que debían dar, Ninconyancu se dirigió al general, y le dijo, que los Pehuenches, á ecepcion de tres caciques á los cuales el resto sabían como contener, aceptaban sus proposiciones. Entonces todos se levantáron de sus asientos, acepto los tras caciques que no opinaban como la mayoría, y en testimonio de su sinceridad abrazáron al general. Sin perder un instante el casique Mellyagin salió á comunicar á los Indios que estaban en la esplanada, que las proposiciones de los Cristianos eran tales que podían admitirse. Estos inmediatamente quitaron las sillas á sus caballos, y se los entregaron á los milicianos para que los sacáran á pacer, y en seguida fuéron depositados sus lanzas, hachas y cuchillos (sus únicas armas) en un cuarto para tenerlas guardadas alli hasta la conclusion de las borracheras, que infaliblemente se siguen á toda conferencia a esta especie [...] Consagraron un dia al cambio de presentes. Cada cacique regaló al general un poncho hilado, tejido y hecho por sus mujeres [...] Alguno de los ponchos que aceptó el general no carecian de merito, particularmente en la viveza del dibujo, y la permanencia de los colores. Lo que parecía apreciaron mas los Indios de los regalos que recibiéron, fueron los sombreros y los vestidos bordados ó galoneados [...] A los dos dias de la llegada de los Indios parió una de la mugeres El zeloso padre Julian no quiso perder la oportunidad de arrancar el alma del chiquillo de las "garras de Satan", y empleando una piadosa extratagema lo tomó como para enseñarlo á los compañeros, y lo bautizó en el cuarto del general, del cual alcanzó fuese su padrino (Miller, [1828] 1997: 119-124).

Además, Miller describió la fiesta que realizaron los indígenas, aspectos socioculturales y territoriales de los pehuenches, y que en el parlamento participaron un total de dos mil personas. Jimena Pichinao Huenchuleo plantea 
que en los parlamentos existía un protocolo que iba "desde las invitaciones, saludos de bienvenida, localización de los invitados, designación y pronunciación de nombres, discursividad, hasta la comensalidad y la despedida de los invitados" (2012: 33). Como se puede observar en parte de lo redactado por Miller el parlamento tuvo un tiempo, una lógica, y se desenvolvió a partir de una estructura especifica ritual implícita y conocida por los participantes: la llegada de los indígenas al fuerte, el desfile militar, la presentación de los caciques y su comitiva, la escenificación de un acto de combate por parte de los mismos y la respuesta mediante el disparo de cañones y pistolas por parte de los criollos; la conferencia entre los principales caciques y San Martín y su comitiva, en donde los criollos realizaron sus proposiciones y los indígenas se presentaron, expusieron sus opiniones y debatieron entre sí; los festejos de los indígenas luego de aceptar las propuestas de los criollos y la entrega de regalos entre las partes como forma de finalizar el parlamento. Además, en este caso se suma -se podría suponer de forma fortuita en esta ocasión- una forma adicional de parentesco entre las partes: el padrinazgo de un bebé por parte de San Martín.

Ricardo Rojas retomó este evento y planteó que participaron más de cincuenta Caciques "que señoreaban en los valles andinos del sur" ([1933] 1961: 137) entre los que se encontraban: Ancain, Antepan, Calimilla, Goyco, Jamin, Epiman, Huanguenecul, Manquepi, Marilinco Millatur, Necuñan, Neyancari y Peñalef, además de Inalican. A pesar de lo planteado por Rojas no hemos encontrado ni la cantidad ni los nombres de los participantes y solamente podemos inferir que del lado de los indígenas participaron Neycuñan, Millaguin, Pañichiñe -quienes eran para aquel momento los principales líderes indígenas y sin los cuales ningún trato diplomático hubiera tenido demasiado éxito- y Millalican, ${ }^{36}$ quien seguramente ofició, junto a su primo Inalican, de traductor y secretario de los Caciques y Capitanejos. En cuanto a los patriotas podemos inferir que además de San Martín y su guardia de Granaderos, como mínimo tuvo que haber participado el Comandante del fuerte, Lemos. Otro aspecto que podemos inferir es su duración, la cual se habría extendido durante seis días ya que comenzó el 18 de septiembre y terminó el día 23 de ese mismo mes. Al igual que en el parlamento de 1814, los pehuenches dieron muestra de aceptar las propuestas de los criollos. ${ }^{37}$

Existen algunos indicios de que los elementos llevados por San Martín para regalarles a los pehuenches no habrían alcanzado o no los habrían satisfecho en su totalidad, ya que en días siguientes recibieron algunos víveres más. ${ }^{38} \mathrm{~A}$ esto se le suma un mensaje del propio Pablo Millalican dirigido al gobierno de Mendoza en donde expresa la situación:

Siendo yo Comisionado, Pr. los Superiores ${ }^{e}$ de $S^{n}$. Carlos, á encontrar á los Casiques para selebrar el parlamento $\mathrm{q}^{\mathrm{e}}$. se berifico á $18 \mathrm{de} \mathrm{Sept}^{\mathrm{e}}$., viendo en mi Venida, escaces de Viveres a si los Casiques y moseton ${ }^{\text {es }}$. ordene tomasen dos Reses, en la hacienda de $\mathrm{D}^{\mathrm{n}}$. Joseh Marcos Sayesm y $\mathrm{p}^{\mathrm{a}}$. su costamen doy este á 25 de dho mes del $1816 .{ }^{39}$

Otro aspecto de especial interés en torno al intercambio de regalos en el parlamento es la entrega de ponchos por parte de los indígenas a San Martín. Recientemente, miembros de la Comunidad Malalweche ${ }^{40}$ mencionaron que en este parlamento las parcialidades le entregaron un poncho o makuñ a San Martín como muestra de respeto y alianza, mediante el cual lo consideraban como un aliado del pueblo pehuenche (Roulet, 2016) o como uno de sus líderes, idea que es retomada por Martínez Sarasola (2014). La textilería al interior
36. AGPM, PI, Carpeta 240, Doc. 24, F. 18,23 de septiembre de 1816 y Carpeta 485 , Doc. 38, F. 277, 19 de octubre de 1816.

37. Esto se puede apreciar en la carta enviada por San Martín a Tomas Guido luego de haber realizado lo que el General patriota denominó como "Gran Parlamento" (PascuaIli, 2000: 67).

38. AGN, Sala X, 4-3-5, F. 422.

39. AGN, Sala X, 4-3-5; F. 427. Pablo Millalican al Gobierno de Mendoza. 25 de septiembre de 1816 .

40. Canal Encuentro, San Martín y los pehuenches: cruce de los Andes. Disponible en Internet: https:// www.youtube.com/watch?v=fltBKY swcbM\&fbclid=IwAR354pIDsljFFtS VyPeZrJxlliHgeswZITMZjBxRgMnT WasbTuzqodBPRHI\&app=desktop. Consultada el: 28 de enero de 2020. 
41. Realizada en el marco de un relevamiento de los ponchos existente en el Museo Histórico Nacional en el 2017.

42. El toqui o toki hace referencia tanto al máximo rango militar entre los mapuches como a una clava o hacha de piedra que oficiaba de símbolo de la más alta figura militar (Zavala Cepeda, 2008). En ocasiones se hace mención a la primera acepción como toki general o gentoki para referirse al rango mientras que para referirse a la clava se utiliza la denominación toki cura.

43. Existen varias referencias que vinculan a los ponchos de color azul con líderes tanto indígenas como hispanos-criollos, por ejemplo, Choeque (Musters, [1871] 2007; Hux, 2007); Catriel (Hux, 2007) y José Francisco Amigorena (Sosa Morales, 1965; Hux, 2007; Roulet, 2016). Con respecto a este último, Sosa Morales (1965), Hux (2007) y Roulet (2016) sostienen que fue enterrado con dos ponchos azules confeccionados por la Cacique María Josefa Roco. Según Megue Roso (2004), el kalfu, color azul, para el pueblo mapuche está vinculado al espacio sacro del cielo y al agua y, por consiguiente, asociado a valores positivos. Además, en el caso del poncho regalado a San Martín tenemos que agregar que este posee un campo de color blanco, el cual tendría un valor cuasi religioso (Conejero, 2004). Por otro lado, Pablo Lacoste y Michelle Malén Lacoste Adunka (2018) advierten que dentro de los ponchos mapuches era recurrente el color azul, seguramente por la simpatía que los indígenas sentían por el añil. Además, ambos autores señalan la importancia que tenían los ponchos mapuches en la vida cotidiana y en la economía de los hispano-criollos durante las primeras décadas del siglo XIX, especialmente por su gran calidad.

44. Los costos y elementos para confeccionarla constan en el AGN, Sala X, 4-3-5, F. 429, 21 de octubre de 1816 .

45. AGPM; PI; Carpeta 243, Doc. 1, F.9. 10 de noviembre de 1819. Francisco Inalican a Toribio Luzuriaga (Pavez Ojeda, 2008). del pueblo mapuche sirvió, y sirve, para transmitir mensajes, ocupando los ponchos un lugar privilegiado al interior de este sistema, en donde se combinaba el uso de los colores y figuras para transmitir mensajes específicos a quienes pudieran leerlos. Los makúñ son prendas masculinas con un alto contenido simbólico usadas, por lo general, por personas de gran importancia dentro de las parcialidades indígenas (Conejeros, 2004; Fiadone, 2007; Pichinao Huenchuleo, 2012). Las fuentes son particularmente parcas sobre la utilización del makúñ por parte de San Martín y se sabe realmente poco sobre esta prenda, la cual actualmente se encuentra en custodia del Museo Histórico Nacional (Argentina). Según la ficha ( ${ }^{\circ}$ F1288) de este poncho, ${ }^{41}$ fue donado a la institución en 1890 por parte de la Presidencia de la Nación; data entre 1815 y 1820; posee una medida de $166 \mathrm{~cm}$ de largo por $163 \mathrm{~cm}$ de ancho; es de pelo de camélido y predominan el color blanco, azul, verde, violeta y negro. Pedro Mege Rosso (1998) ha realizado un análisis del simbolismo existente en dicho poncho llegando a la conclusión de que se trata de una prenda con una gran carga simbólica perteneciente a un alto líder dentro de los mapuches, al punto de que el autor del análisis plantea la posibilidad de equiparar a San Martín con un toqui, ${ }^{42}$ o jefe militar mapuche. ${ }^{43}$ En contraposición, el por entonces Gobernador de Mendoza y Jefe del Ejército de los Andes prometió a Neycuñan obsequiarle "una media levita de panete encarnado con su galon", 44 la cual fue entregada al Cacique Gobernador a mediados del mes siguiente.

Como se aprecia según los diversos elementos planteados hasta el momento, si bien el parlamento entre los pehuenches y San Martín fue un evento con una gran carga simbólica propia respondió a fines políticos, económicos y culturales inscriptos dentro de una lógica fronteriza más amplia. Entendemos que además de los aspectos militares y estratégicos, de pedir permiso para que una de las seis columnas del Ejercito de los Andes -la de Freire- pasase por los territorios indígenas, este evento actuó como una reactualización de las alianzas políticas y militares entre indígenas y patriotas. También ofició como forma de etiqueta y agradecimiento por parte San Martín hacia los principales Caciques y Capitanejos pehuenches por la captura de un enemigo tan importante para la causa patriota, como lo fue Huici. La captura de este Coronel realista fue tan importante que el propio Neycuñan les recordó a los patriotas, tres años después, la colaboración indígena en este evento. ${ }^{45}$ Estos últimos eran actores independientes y autónomos, con territorios e instituciones políticas propias, por lo tanto el parlamento actuó como un encuentro entre dos naciones independientes, autónomas entre sí pero vinculadas por relaciones diplomáticas que debían actualizarse y "aceitarse" de forma asidua.

\section{Conclusiones}

El parlamento realizado en 1816 entre parcialidades pehuenches y San Martín lejos estuvo de tener como finalidad engañar a los primeros, encuadrándolo en la "guerra de zapa". Para los indígenas fue una oportunidad de reclamar la recompensa por haber atrapado a Huici, prometida por los criollos, y de reafirmar su autonomía política y territorial; mientras que para los patriotas fue una forma de mantener las alianzas con un actor político-económico de gran importancia. El análisis de las fuentes documentales sugiere pensar este parlamento en el marco de una dinámica mayor que responde a lógicas propias de la diplomacia fronteriza en Cuyo, construida desde larga data y que vinculó a dos grupos autónomos pero estrechamente relacionados por alianzas políticas, comercio y hasta lazos parentales. Tanto indígenas como patriotas poseían sus propias agencias políticas y sociales pero desde hacía 
varios años venían construyendo y manteniendo una alianza, la cual se tenía que actualizar constantemente a raíz de las tensiones interétnicas. De hecho, dicha alianza no estuvo exenta de roces cotidianos entre indígenas y criollos y se tenía que respetar y reactualizar constantemente.

En este parlamento, al igual que en los anteriores de 1812 y 1814, tuvieron gran importancia los intermediarios fronterizos, conocedores de los "protocolos de tierra adentro". Entre los indígenas fueron los principales Caciques los que actuaron de intermediarios fronterizos, como Neycuñan, Millaguin y Pañichiñe. Por parte de los criollos este rol lo desempeñaron aquellos funcionarios que ocuparon posiciones de contacto directo con el mundo indígena como el Capitán de Amigos, los Comandantes de Frontera y de los fuertes o los curas conversores.

A su vez, el encuentro de 1816 sirvió a las parcialidades pehuenches para continuar las negociaciones con los patriotas y recordarles que ellos cumplían lo pactado en años anteriores, siendo también una forma de presionar a los criollos para que cumplan su parte de lo acordado tiempo atrás. No obstante, en este parlamento también se manifestaron las tensiones al interior de los pehuenches y sus posturas disimiles con respecto a las alianzas con los patriotas, como sucedió con los tres Caciques que se opusieron a lo pactado en el parlamento. Desde el punto de vista patriota, si bien este encuentro fue útil con respecto a cuestiones militares -tal como lo expresó San Martín en varias comunicaciones con sus hombres de confianza- su valor residió en su carácter político. Este encuentro les sirvió para reactualizar las alianzas políticas con las parcialidades pehuenches y así seguir manteniendo una relativa paz en la frontera.

De modo que lo acontecido en 1816 es una pieza más del rompecabezas de las relaciones fronterizas que se fueron construyendo durante fines del periodo colonial y comienzos del republicano en el sur de Cuyo, donde los pehuenches tuvieron un papel crucial como agentes políticos y militares. El parlamento de ese año no fue producto de un acto altruista ni un intento de engaño por parte de los patriotas sino que fue el resultado de una lógica fronteriza en donde existía una paridad de fuerzas interétnicas. En este contexto los indígenas jugaron un papel protagónico a la hora de disputar, mantener y proteger sus territorios e intereses políticos ante el avance de los sectores patriotas y realistas. La autonomía de la agencia indígena durante estos años les permitió a las distintas parcialidades negociar de igual a igual con hispanos y criollos con el fin de proteger sus espacios políticos, económicos, sociales y territoriales. Esta situación comenzó a deteriorarse hacia la década de 1820, época en donde se reactivaron los proyectos de los criollos de avanzar sobre "tierra adentro", lo que culminó con la campaña militar de 1833 y una perdida sustancial, aunque no total, de la autonomía indígena al sur de Mendoza. 
2. Por otro, hemos podido ver que recién aparece mencionado en el mapa de Mendoza de 1888 elaborado por Mariano Felipe Paz Soldán y editado por Félix Gajouane. Disponible en Internet: https://www.davidrumsey.com/ luna/servlet/detail/RUMSEY 8 1 20647 570024:Provincia-de-Mendoza?sort=Pub_List_No_InitialSort\%2CPub_Date\%2CPub_List_No\%2CSeries_ No\&qvq=q:mendoza; sort:Pub_List_No_InitialSort\%2CPub_Date\%2CPub_ List_No\%2CSeries_No; Ic:RUMSEY 8 1\&mi=97\&trs=101. Consultada el: 20 de enero de 2020. (En página 75).

4. Fondo Tomas Guido, Correspondencia con José de San Martín; T.1; Pág. 29 (utilizada por Mitre, Barros Arana, Espejo y Yrarrázaval Larraín); Carta de San Martín a Martín Pueyrredón fechada el 10 de septiembre 1816 (utilizada por Barro Arana Tomo X, Espejo, Yrarrázaval Larraín) y la respuesta de Pueyrredón a San Martín fechada el 1 de octubre de 1816 (utilizada por Yrarrázaval Larraín); Carta de San Martín a Marcó, sin fecha (utilizada por Mitre); Carta de San Martín a Godoy Cruz fechada el 10 de septiembre de 1816 (utilizada por Barros Arana Tomo X y Yrarrázaval Larraín). (En página 75). 


\section{Bibliografía citada}

» Avila Martel, A. D. (1973). “Régimen jurídico de la guerra de Arauco" en III Congreso del Instituto Internacional de Historia del Derecho Indiano: actas y estudios: 325-338. Madrid, Instituto Nacional de Estudios Jurídicos.

» Barbuto, L. (2016). “Diplomacia, Mediadores, y Política en la Frontera Sur de Buenos Aires (1860-1870)" en De Jong, I (comp.), Diplomacia, Malones y Cautivos en la Frontera Sur, Siglo XIX. Miradas Desde la Antropología Histórica: 159-216. Buenos Aires, Sociedad Argentina de Antropología.

»Barros Arana, D. (1857). Historia Jeneral de la Independencia de Chile. Tomo III. Santiago, Imprenta del Ferrocarril.

» Barros Arana, D. (1889). Historia Jeneral de Chile. Tomo X. Santiago, Rafael Joven Editor.

» Bechis, M. (2001). “De hermanos a enemigos: los comienzos del conflicto entre los criollos republicanos y los aborígenes del área Arauco-Pampeana, 1814-1818" en Bandieri, S. (coord.), Cruzando la Cordillera: la frontera argentino-chilena como espacio social: 6599. Neuquén, Centro De Estudios De Historia Regional, Facultad De Humanidades, Universidad Nacional Del Comahue.

» Boccara, G. (2002). “Colonización, resistencia y etnogénesis en las fronteras” en Boccara, G. (ed.), Colonización, resistencia y mestizaje en las Américas (Siglos XVI-XX): 4782. Quito, Editorial Abya-Yala/ Instituto Francés de Estudios Andinos.

» Bragoni, B. (2010). San Martín: de soldado del rey a héroe de la nación. Buenos Aires, Sudamericana.

» Conejeros, R. (2004). “Divinidades en el arte textil delPuelMapu (Tierra del Este)" en Llamazares, A. M. y Martínez Sarasola, C. (eds.), El lenguaje de los dioses. Arte, chamanismo y cosmovisión indígena en Sudamérica: 199-226. Buenos Aires, Biblos.

»Chaca, D. (1964). Síntesis histórica del departamento de San Carlos. Acompañado de un abundante apéndice documental. Buenos Aires, Talleres Gráficos Juan Castañola e hijos.

»De Jong, I. (2016). Prácticas de la diplomacia fronteriza en las Pampas, siglo XIX. Revista Habitus. Revista do Instituto Goiano de Pré-História e Antropologia. 14 (2): 175-197.

»Documentos para la historia del Libertador General San Martín (1954), T. IV. Buenos Aires, Ministerio de Educación de la Nación. Instituto Nacional Sanmartiniano y Museo Histórico Nacional.

»Espejo, J. (1882). El paso de los Andes. Buenos Aires, Imprenta y Librería Mayo.

»Fiadone, A. E. (2007). Simbología mapuche en territorio tehuelche. Buenos Aires, Maizal.

»Galasso, N. (2007). Seamos libres y lo demás no importa nada. Buenos Aires, Colihue.

» Gattas, Orlando J. (2018). Historia de San Carlos. Relación e integración con la región, Argentina y el mundo. Mendoza, Municipalidad de San Carlos. Disponible en Internet: https://issuu.com/sancarlos.historia/docs/scb?issuu_product=document_page\& issuu_context=action\&issuu_cta=follow_publisher. Consultada el: 25 de enero 2020.

»Hux, M. (2007). Caciques y capitanejos de la llanura del Plata. Manuscrito.

» Junta de Historia y Numismática Americana (1911). La Gaceta de Buenos Aires (1810-1821). Tomo III (1811 a 1813), Buenos Aires.

» Lacoste, P. y M. M. Lacoste Adunka (2018). Chamantos, Ponchos y Balandres en 
Colchagua y Rancagua (siglos XVII-XIX). Estudios atacameños 57: 97-118.

"Lázaro, C. A. (2002). "El parlamentarismo fronterizo en la Araucanía y las Pampas” en Boccara, G. (comp.), Colonización, resistencia y mestizaje en las Américas, siglos XVI-XX: 201-236. Quito, Ediciones Abya-Yala/ Instituto Francés de Estudios Andinos.

» León, L. (2001). Los señores de la cordillera y las pampas: los pehuenches de Malalhue 1770180o. Mendoza, Universidad de Congreso.

» Levaggi, A. (1992). Muerte y resurrección del Derecho Indiano sobre el aborigen en la Argentina del siglo XIX. Jahrbuch für Geschichte Lateinamerikas 29: 179-193.

" Levaggi, A. (1993). Los tratados entre la Corona y los indios y el plan de conquista pacífica. Revista complutense de historia de América 19: 81-91.

» Levaggi, A. (1995). “Tratados entre la Corona y los indios de la frontera sur de Buenos Aires, Córdoba y Cuyo" en Memoria del X Congreso del Instituto Internacional de Historia del Derecho Indiano: 695-764. México, Universidad Nacional Autónoma de México.

"Levaggi, A. (200o). Paz en la frontera. Historia de las relaciones diplomáticas con las comunidades indígenas en la Argentina (Siglos XVI-XIX). Buenos Aires, Universidad del Museo Social Argentino.

" Martínez Sarasola, C. (2014). La Argentina de los caciques o el país que no fue. Buenos Aires, Editorial del Nuevo Extremo.

» Mege Rosso, P. (1998). La manta del libertador: legado de la expresión textil Mapuche. Boletín del Museo Chileno de Arte Precolombino 7: 53-65.

» Mege Rosso, P. (2004). “Colores aquí. Simbología mapuche del color” en Llamazares, A. M. y Martínez Sarasola, C. (eds.), El lenguaje de los dioses. Arte, chamanismo y cosmovisión indígena en Sudamérica: 247-258. Buenos Aires, Biblos.

» Méndez, L. M. (1982). “La organización de los parlamentos de indios en el siglo XVIII” en Villalobos, S. (comp.), Relaciones fronterizas en la Araucania: 107-174. Santiago de Chile, Universidad Católica de Chile.

» Miller, J. ([1828] 1997). Memorias del general Guillermo Miller. Buenos Aires, Editorial Emecé.

» Miranda Borelli, J. (1984). Tratados de paz realizados con los indígenas en la Argentina (1597-1875). Suplemento antropológico19: 233-284.

» Mitre, B. ([1875-1887] 1968). Historia de San Martín y de la emancipación Sudamericana. Buenos Aires, EUDEBA.

» Molina, E. (2014). Justicia de proximidad y gobierno político-militar en la frontera. Equipamiento institucional del Valle de Uco (Mendoza) durante el proceso revolucionario (1810-1820). Mundo agrario 30 (15): 1-29.

» Morales Guiñazú, F. (1938). Primitivos habitantes de Mendoza. Mendoza, Best Hnos.

» Musicó, A. M. (1973). “Relaciones pacíficas con los aborígenes” en Comando General del Ejército. Política seguida con el aborigen (1750-1819), T. 1 (654-655): 541-546. Buenos Aires, Círculo Militar.

» Musters, G. ([1871] 2007). Vida entre los patagones. Un año de excursiones desde el estrecho de Magallanes hasta el río Negro (1869-1870). Buenos Aires, Ediciones Continente.

» Nacuzzi, L. R. (2006). Tratados de paz, grupos étnicos y territorios en disputa a fines del siglo XVIII. Investigaciones sociales 10 (17): 435-456.

» Olazábal, M. ([1855] 1978). Episodios de la guerra de la independencia. Buenos Aires, Instituto Nacional Sanmartiniano. 
»Pasquali, P. S. (2000). San Martín, confidencial: correspondencia personal del Libertador con su amigo Tomás Guido (1816-1849). Buenos Aires, Planeta.

»Pavez Ojeda, J. (2008). Cartas Mapuches. Siglo XIX. Santiago de Chile, Colibris Éditions.

» Pérez, F., I (1996). El Fuerte de San Carlos. Crónicas de la Frontera y de la Campaña. Serie: Investigaciones $\mathrm{N}^{\circ}$. Mendoza, Archivo Histórico de Mendoza.

» Piattelli, A. (2014). San Martín en el Valle de Uco. Valores, ideales, vida y obra del padre de la patria. San Carlos, Mendoza, Zeta Editores.

» Pichinao Huenchuleo, J. (2012). “Los parlamentos hispano-Mapuche como escenario de negociación simbólico político durante la colonia” en Nahuelpan, N. Huinca, H., Marimán, P., Cárcamo-Huechante, L., Mora, M., Quidel, J. Antileo, E., Curivil, F., Huenul, S., Millalén, J., Calfio, M., Pichinao, J., Paillan, E y A. Cuyul (eds.), Historia, colonialismo y resistencia desde el país mapuche: 25-42. Temuco, Ediciones Comunidad de Historia Mapuche.

» Rojas, R. ([1933] 1961). El Santo de la Espada. Buenos Aires, Editorial Guillermo Kraft.

» Roulet, F. (1999-2001). De cautivos a aliados: los indios fronterizos de Mendoza (17801806). Revista Xama 12-14: 199-239.

» Roulet, F. (2002). “Guerra y diplomacia en la frontera de Mendoza: la política indígena del Comandante José Francisco de Amigorena” en Nacuzzi, L. (comp.), Funcionarios, diplomáticos y guerreros. Miradas hacia el otro en las fronteras de Pampa y Patagonia (Siglos XVIII y XIX): 65-118. Buenos Aires, Publicaciones Sociedad Argentina de Antropología.

» Roulet, F. (2004). Con la pluma y la palabra. El lado oscuro de las negociaciones de paz entre españoles e indígenas. Revista de Indias 231 (64): 313-348.

» Roulet, F. (2014). Fronteras de papel. El periplo semántico de una palabra en la documentación relativa a la frontera sur rioplatense de los siglos XVIII y XIX. Revista Tefros 4 (2): 1-26.

» Roulet, F. (2016). Huincas en tierras de indios. Buenos Aires, Eudeba.

»Sosa Morales, N. (1965). El muy magnífico señor don José Francisco de Amigorena: Cuyo durante la intendencia de Córdoba. Córdoba, Cangioli.

»Vignati, M. A. (1953). Datos de etnografía pehuenche del libertador José de San Martín. Notas del Museo de Eva Perón XVI: 1-22.

»Villegas, A. (1947). Un documento de San Martín con referencias históricas. Sociedad de Historia Argentina. Anuario V: 345-377.

» Yrarrázaval Larraín, J. M. (1949). San Martín y sus enigmas (Vols. 1 y 2). Santiago de Chile, Nascimento.

»Zavala Cepeda, J. M. (2008). Los mapuches del siglo XVIII. Dinámica interétnica y estrategias de resistencia. Santiago de Chile, Editorial Universidad Bolivariana.

» Zavala Cepeda, J. M., Dillehay, T., Puigarnau, G. P. \& F. Le Bonniec (2015). “Los parlamentos hispano-mapuches como espacios de reconocimiento de otro enemigo: huellas históricas, lingüísticas y territoriales” en Alonso Araguás, I., Páez Rodríguez, A. y M. Samaniego Sastre (eds), Traducción y representaciones del conflicto desde España y América: 35-48. Salamanca, Ediciones Universidad de Salamanca.

»Zinny, A. (1987). Historia de los gobernadores de las provincias argentinas. Buenos Aires, Hyspamerica. 